\title{
Effect of Crêpe Texture on Tensile Properties of Cotton Fabric under Varied Relative Humidity
}

Htike HH, Kang J, Yokura $\mathbf{H}$ and Sukigara S* $^{*}$

Kyoto Institute of Technology, Kyoto, Japan

\begin{abstract}
The physical properties of cotton crêpe fabrics with highly twisted weft yarn (2200 twists per meter) were evaluated after special embossed finishing to generate piqué. The effect of piqué was investigated as the main factor affecting the tensile properties of the sample fabrics under varied relative humidity. First, the mechanical and surface properties were measured using the Kawabata Evaluation System for Fabrics under standard room conditions, and then, the other physical properties were examined. The existence of piqué in the crêpe texture significantly changed the samples' tensile properties, such as tensile energy and extensibility at maximum applied load (EM) in the weft direction. Additional tensile measurements were carried out under varied relative humidity $(10-90 \% \mathrm{RH})$ at $25^{\circ} \mathrm{C}$. The crêpe fabrics with piqué had higher EM and residual strain values than the non-piqué samples under all $\mathrm{RH}$ conditions. In particular, the effect of piqué on EM became obvious at $90 \% \mathrm{RH}$.
\end{abstract}

Keywords: Crêpe texture; Tensile properties; Relative humidity; Embossed finishing

\section{Introduction}

An advantage of textiles is that their mechanical properties can be modified by varying the constituent yarns and weave structure. Crêpe fabrics made from highly twisted yarns exhibit a variety of wrinkly structures. Such fabrics are produced by using (1) hard-twist filling yarns, (2) chemical treatment, (3) crêpe weaves, and (4) embossing [1]. Japanese cotton crêpe, called Takashima chijimi, is made by employing twisted yarns in both the warp and the weft; however, the weft yarn twist is more than 2000 twists per meter. Such cotton fabrics, which combine hard-twist filling yarns and weave density, are popular materials for men's summer wear. Consumer demand for more attractive crêpe fabrics and new products signifies a shift in preference from casual cotton wear to more formal outerwear, women's dresses, and summer jackets. Accordingly, uniformly ribbed crêpe texture has been designed via additional embossed finishing of basic crêpe weave fabrics with piqué. The number of uniform ribs in piqué crêpe fabrics may govern not only the design but also the physical properties of the fabrics.

From the perspective of fabric weave design, the fundamental relationships among crêpe appearance, yarn twist level, yarn count, and finishing have been reported [2-6]. These findings are useful for achieving the required crinkly design with respect to the effect of twisted yarn shrinkage on fabric crinkling after finishing $[7,8]$. Yokura et al. tried to establish the silhouette and handle design of silk chirimen fabrics for women's thin dresses on the basis of the mechanical properties of these fabrics [9]. In previous reports, the mechanical properties of crêpe fabrics have been measured under standard temperature and humidity conditions (e.g., around $20 \pm 3^{\circ} \mathrm{C}$ and $65 \% \mathrm{RH}$ ). However, cotton fabrics are moisturesensitive materials; thus, the effect of environmental humidity cannot be ignored. One advantage of crêpe fabrics is their high extensibility along the weft direction. In addition, it is necessary to investigate the effect of relative humidity on the tensile deformation of crêpe fabrics used in attire that is comfortable for hot and humid weather. In this study, the surface and mechanical properties of cotton crêpe fabrics were measured using the Kawabata Evaluation System for Fabrics (KES-FB) in order to investigate the most distinctive characteristics of these fabrics. Then, the tensile extensibility and recovery of the fabrics were measured under varied relative humidity conditions. The objective of this study was to determine the influence of relative humidity on the tensile properties of piqué crêpe fabrics.

\section{Materials and Methods}

\section{Samples}

Crêpe appearance is governed by the yarn twist level and finishing. A plain weave gray fabric (S1,40Ne:147.64dtex) was finished by four different processes in order to change its appearance, as shown in Figure 1. Three samples (S1-2, S1-3, and S1-4) were processed with an embossing roller, and two of them (S1-2 and S1-3) were additionally accompanied with piqué. S1-5 was treated via normal finishing without embossing. Plain weave fabric (S0) using the same warp yarn as the crêpe fabric was also produced for comparison. The specifications of the samples are listed in Table 1.

Figure 2 shows microscopic images of the fabrics captured using a 3D microscope (VR-3000 series, Keyence). Traces along the warp and weft yarn directions as well as those between the yarns are shown in this figure. The images of samples S1-4 and S1-5 show a randomly bumpy appearance, whereas uniformly ribbed structures are seen for samples S1-2 and S1-3.

\section{Measurement of physical properties of samples}

The physical properties of the samples were examined at $25 \pm 2{ }^{\circ} \mathrm{C}$ and $50-60 \%$ RH by using KES-FB testers (Kato Tech Co., Ltd.). The specific characteristic values, measurement conditions, and KES-FB testers are listed in Table 2. The properties of standard-size samples $(20 \mathrm{~cm} \times 20 \mathrm{~cm})$ were measured three times in the warp direction and three times in the weft directions with a different position used for each measurement.

*Corresponding author: Sachiko Sukigara, Kyoto Institute of Technology, Kyoto Japan, Tel: +81 (75) 724-7365; E-mail: sukigara@kit.ac.jp

Received November 09, 2015; Accepted November 25, 2015; Published December 02, 2015

Citation: Htike HH, Kang J, Yokura H, Sukigara S (2015) Effect of Crêpe Texture on Tensile Properties of Cotton Fabric under Varied Relative Humidity. J Textile Sci Eng 5: 223 doi:10.4172/2165-8064.1000223

Copyright: (c) $2015 \mathrm{Htike} \mathrm{HH}$, et al. This is an open-access article distributed under the terms of the Creative Commons Attribution License, which permits unrestricted use, distribution, and reproduction in any medium, provided the original author and source are credited. 


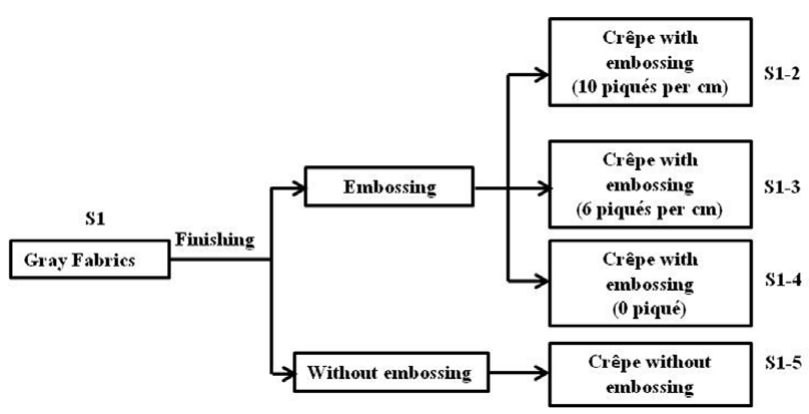

Figure 1: Process for producing samples.

\begin{tabular}{|c|c|c|c|c|c|c|c|}
\hline \multirow{2}{*}{$\begin{array}{c}\text { Sample } \\
\text { no. }\end{array}$} & Structure & & \multicolumn{3}{|c|}{ Weave density/cm } & $\begin{array}{c}\text { Weight } \\
\text { (mg/cm } \mathbf{~}\end{array}$ & $\begin{array}{c}\text { Thickness } \\
\text { (mm) }\end{array}$ \\
\hline S0 & Plain & & 38 & 29 & 9.91 & 0.46 \\
\hline S1 & Gray & & 27 & 21 & 8.09 & 0.49 \\
\hline S1-2 & $\begin{array}{l}\text { Crêpe with } \\
\text { embossing }\end{array}$ & 10 & 40 & 22 & 10.64 & 0.93 \\
\hline S1-3 & $\begin{array}{c}\text { Crêpe with } \\
\text { embossing }\end{array}$ & 6 & 36 & 22 & 9.85 & 0.91 \\
\hline S1-4 & $\begin{array}{c}\text { Crêpe with } \\
\text { embossing }\end{array}$ & 0 & 34 & 22 & 9.71 & 0.76 \\
\hline S1-5 & $\begin{array}{c}\text { Crêpe } \\
\text { without } \\
\text { embossing }\end{array}$ & & 32 & 22 & 9.67 & 0.97 \\
\hline
\end{tabular}

Yarn twist - S0: 1000 twists per meter (warp and weft)

S1 S1-5: warp, 1000 twists per meter; weft, 2200 twists per meter Yarn linear density - warp, weft: 147.64 dtex

Table 1: Specifications of fabric samples.

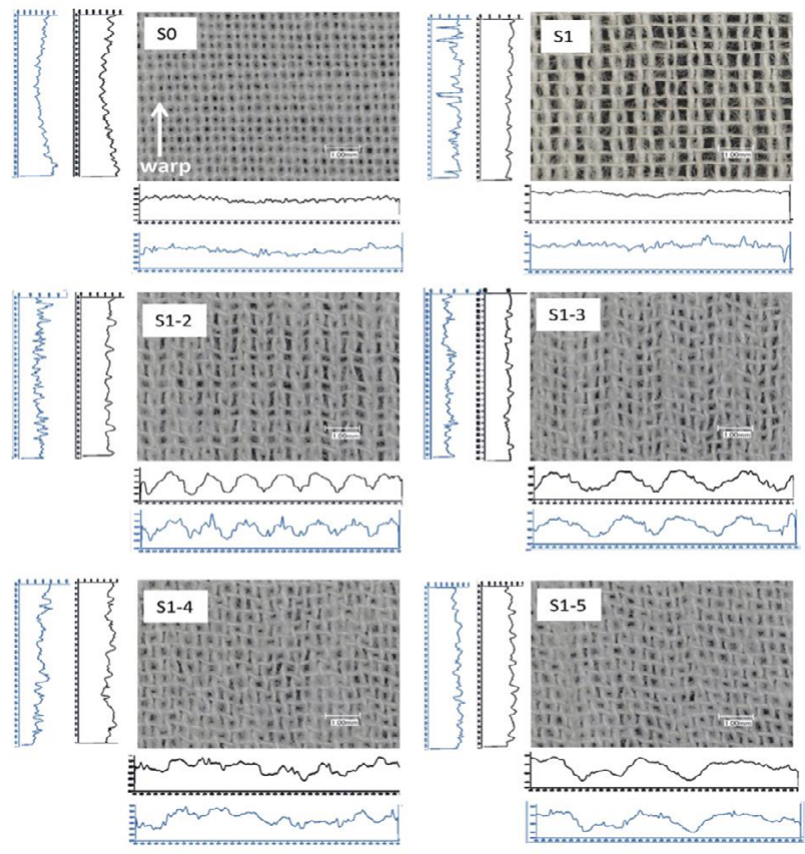

Figure 2: Microscopic images of fabric geometry expressed with traces along warp and weft yarn directions and between yarns. Black curves: traces along the yarns, Blue curves: traces between the yarns.

\section{Fabric tensile test}

Figure 3 shows a schematic of the sample preparation and conditioning for the tensile test. First, the prepared samples $(1 \mathrm{~cm} \times$ $6 \mathrm{~cm}$ ) were dried in an infrared moisture determination balance (FD720 , Kett Electric Laboratory) at $100^{\circ} \mathrm{C}$ for $3 \mathrm{~min}$. Then, the samples were transferred to a chamber with a precisely controlled humidity supply (SRG-10R-AS, Daiichikagaku, Japan) and conditioned for 10 min under $10 \% \mathrm{RH}$. The humidity was increased to preset values of $40 \%, 60 \%, 70 \%, 80 \%$, and $90 \% \mathrm{RH}$ at $25^{\circ} \mathrm{C}$, under which the samples were conditioned for $1 \mathrm{~h}$. For the wet condition, the samples were immersed in water at $25^{\circ} \mathrm{C}$ for $10 \mathrm{~min}$ and measurements were then carried out in the water. The tensile properties were measured using the KES-G1S (Kato Tech Co., Ltd.), which equipped with a humidity control chamber. Loading-unloading cyclic tests were carried out three times at a maximum tensile load of $49 \mathrm{~N} / \mathrm{m}$ and tensile speed of 0.1 $\mathrm{mm} / \mathrm{s}$. The gauge length was $5 \mathrm{~cm}$ and three specimens per sample were measured under each RH condition.

Characteristic values such as extensibility at $49 \mathrm{~N}$ (EM, Percentage), tensile energy up to EM (WT, $\mathrm{J} / \mathrm{m}^{2}$ ), resilience (RT, Percentage) and initial linearity (LT) were calculated following the KES system characterization [10].

\section{Results and Discussion}

\section{Effect of crêpe appearance on mechanical and surface properties}

Figure 4 compares the physical properties of the plain and crêpe fabrics. The horizontal axis represents the difference between the plain fabric (S0) and the crêpe fabrics as a percentage.

- Tensile properties: Extensibility (EM2) and tensile energy (WT2) values of all the crêpe fabrics in the weft direction were significantly larger than those in the warp direction. Furthermore, EM2 and WT2 of the crêpe fabrics were larger than those of the plain fabric.

Under stretching due to tensile force, the wavy parts of the crêpe fabrics were flattened. This phenomenon was more apparent in uniformly ribbed crêpe (i.e., crêpe with piqué structure). This made the pique fabrics more extensible: the higher the number of piqués, the more extensible the fabric. S1-2 (10 piqués per centimeter) had larger EM2 and WT2 values than S1-3 (6 piqués per centimeter). The equidistant ribbed piqué structure of S1-2 and S1-3 made these fabrics extensible by over $400 \%$ as compared to S0. In addition, S1-2 and S1-3 showed larger EM2 and WT2 values than S1-4 and S1-5 (crêpe without piqué). Tensile resilience (RT) reflects the ability of a fabric to recover from tensile deformation. The RT2 values of S1-2, S1-3, S1-4, and S1-5 were $20.00 \%, 26.98 \%, 27.05 \%$, and $23.76 \%$ lower than the RT2 value of S0, respectively. Thus, higher extensibility was accompanied by lower recovery.

- Bending property: The extensibility and bending rigidity of crêpe are influenced by the curvature of interlacing of the weft yarns on the warp yarns as well as by small crinkles on the base fabric. In the case of bending, differences between the piqué and non-piqué fabrics were observed in the warp direction. The warp bending rigidity (B1) and bending hysteresis (2HB1) values of S1-2 and S1-3 were larger than those of S1-4 and S1-5. When the piqué cords along the warp direction were bent, an additional bending moment was created. On the other hand, the waved crêpe fabric was easily bent in the weft direction as compared to the plain fabric. Bending hysteresis represents both the friction between yarns and viscoelastic behavior. The $2 \mathrm{HB}$ values of the 
Citation: Htike HH, Kang J, Yokura H, Sukigara S (2015) Effect of Crêpe Texture on Tensile Properties of Cotton Fabric under Varied Relative Humidity. J Textile Sci Eng 5: 223. doi:10.4172/2165-8064.1000223

Page 3 of 5

\begin{tabular}{|c|c|c|c|c|c|}
\hline Properties & Symbol & Characteristic value & Unit & Measuring conditions & KES machines \\
\hline \multirow[t]{4}{*}{ Tensile } & EM & Strain at maximum load & $\%$ & \multirow{2}{*}{$\begin{array}{l}\text { Strip biaxial deformation } \\
\text { Maximum load: } 49 \mathrm{~N} / \mathrm{m}\end{array}$} & \multirow[t]{4}{*}{ KES-FB1 } \\
\hline & $\mathrm{LT}$ & Linearity & none & & \\
\hline & WT & Tensile energy & $\mathrm{J} / \mathrm{m}^{2}$ & \multirow[t]{2}{*}{ Speed: $0.1 \mathrm{~mm} / \mathrm{s}$} & \\
\hline & RT & Resilience & $\%$ & & \\
\hline \multirow[t]{2}{*}{ Bending } & B & Bending rigidity & $\mu \mathrm{Nm}$ & \multirow{2}{*}{$\begin{array}{c}\text { Pure bending } \\
\text { Maximum curvature } \mathrm{K}: \pm 250 \mathrm{~m}^{-1}\end{array}$} & \multirow[t]{2}{*}{ KES-FB2-S } \\
\hline & $2 \mathrm{HB}$ & Hysteresis of bending moment & $\mathrm{mN}$ & & \\
\hline \multirow[t]{3}{*}{ Shearing } & $\mathrm{G}$ & Shear stiffness & $\mathrm{N} / \mathrm{m}$ & \multirow{3}{*}{$\begin{array}{l}\text { Shear deformation under constant tension } \\
\text { of } 9.8 \mathrm{~N} / \mathrm{m}\end{array}$} & \multirow[t]{3}{*}{ KES-FB1 } \\
\hline & $2 \mathrm{HG}$ & Hysteresis of shear force at $8.7 \mathrm{mrad}$ & $\mathrm{N} / \mathrm{m}$ & & \\
\hline & $2 \mathrm{HG} 5$ & Hysteresis of shear force at $87 \mathrm{mrad}$ & $\mathrm{N} / \mathrm{m}$ & & \\
\hline \multirow[t]{3}{*}{ Compression } & LC & Linearity & none & \multirow{3}{*}{$\begin{array}{l}\text { Maximum pressure: } 0.98 \mathrm{kPa} \\
\text { Rate of compression: } 20 \mu \mathrm{m} / \mathrm{s}\end{array}$} & \multirow[t]{3}{*}{ KES-G5 } \\
\hline & WC & Compression energy & $\mathrm{J} / \mathrm{m}^{2}$ & & \\
\hline & $\mathrm{RC}$ & Resilience & $\%$ & & \\
\hline \multirow[t]{3}{*}{ Surface } & MIU & Coefficient of friction & none & \multirow{2}{*}{$\begin{array}{l}\text { Ten steel piano wires (diameter of a wire: } \\
0.5 \mathrm{~mm} \text {, length: } 1 \mathrm{~cm} \text { ) } \\
\text { Contact force: } 0.49 \mathrm{~N}\end{array}$} & \multirow[t]{2}{*}{ KES-SE-STP } \\
\hline & MMD & Mean deviation of MIU & $\mathrm{J} / \mathrm{m}^{2}$ & & \\
\hline & SMD & Geometrical roughness & $\mu \mathrm{m}$ & $\begin{array}{c}\text { A steel piano wire (diameter: } 0.5 \mathrm{~mm} \text {, } \\
\text { length: } 5 \mathrm{~mm} \text { ) } \\
\text { Contact force: } 0.1 \mathrm{~N}\end{array}$ & KES-SE \\
\hline Air Resistance & $\mathrm{R}$ & Air resistance & $\mathrm{kPa} \cdot \mathrm{s} / \mathrm{m}$ & & KES-F8-AP1 \\
\hline Thickness & T0 & Thickness at $49 \mathrm{~Pa}$ & $\mathrm{~mm}$ & & \\
\hline Weight & W & Weight per unit area & $\mathrm{g} / \mathrm{m}^{2}$ & & \\
\hline
\end{tabular}

Table 2: Physical properties of fabrics measured with the KES-FB system.

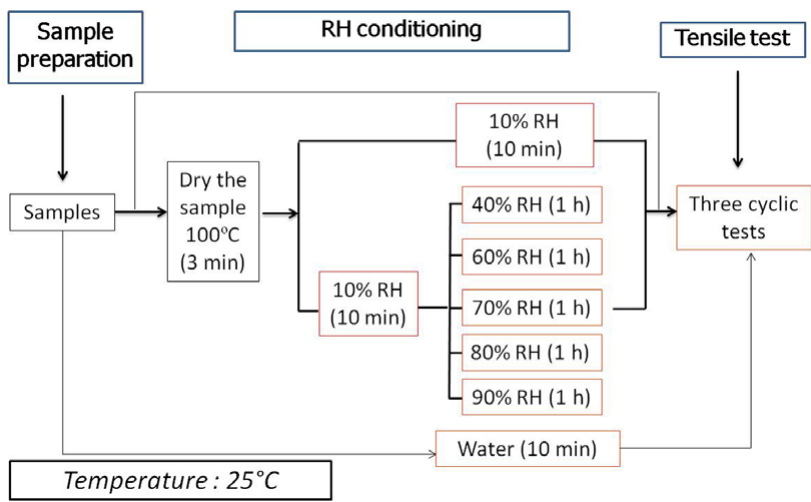

Figure 3: Fabric sample preparation and conditioning prior to the tensile test.

crêpe and piqué crêpe structures were the same as or smaller than those of the plain fabric.

- $\quad$ Shear and compression properties: The shear stiffness and hysteresis of all the crêpe fabrics were smaller than those of the plain fabric. Furthermore, the thickness of the crêpe fabrics was greater than that of the plain fabric because of the bumpy appearance of the crêpe fabrics, as shown in Figure 2. This geometry appeared because of the larger compression energy (WC) of the crêpe fabrics.

- $\quad$ Surface property: The surface property values of all the crêpe samples were larger than those of the plain samples in both the warp and the weft directions. In particular, the surface roughness values of S1-2 (SMD1 and SMD2) were notably larger than those of the other three fabric samples. The surface roughness was measured under a contact force of $0.1 \mathrm{~N}$; thus fine piqué shape was maintained, and the piqué fabrics showed larger SMD values than the other fabrics.

- $\quad$ Air resistance: The air resistance of all the crêpe fabrics was smaller than that of the plain fabrics. Greater spacing was observed

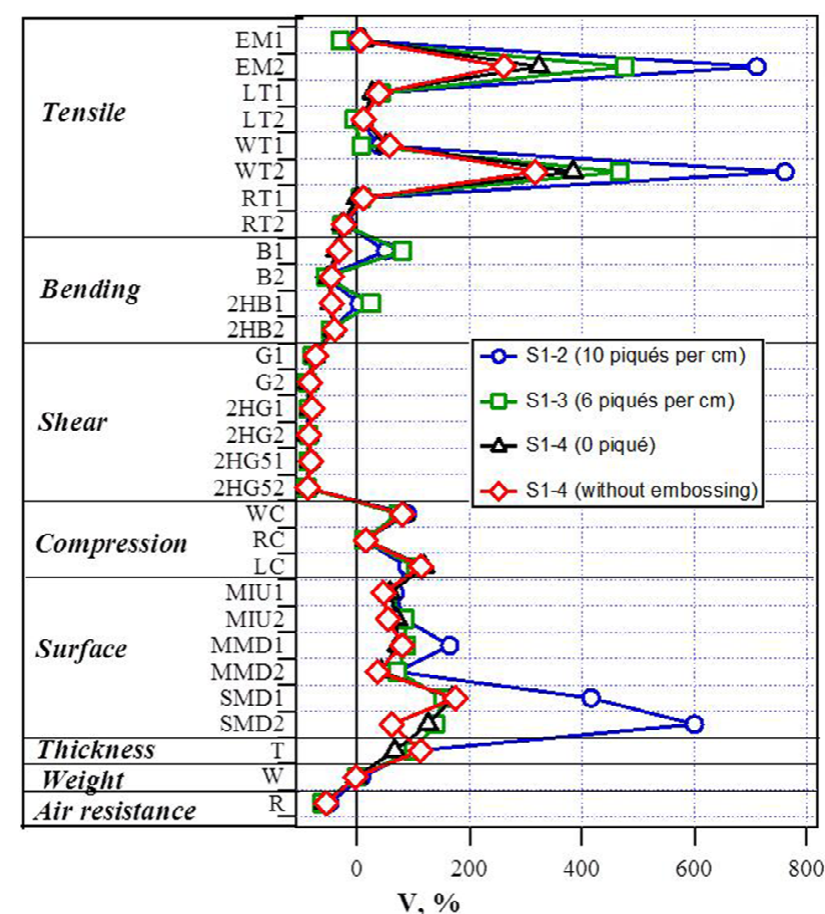

$V=\left(X-X_{p}\right) / X_{p} \times 100 \%$

$X_{P}=$ value of plain fabrics

$\mathrm{X}=$ value of $\mathrm{S} 1-2, \mathrm{~S} 1-3, \mathrm{~S} 1-4, \mathrm{~S} 1-5$

1: warp; 2 : weft; zero line: $V$ values of plain fabrics

Figure 4: Physical properties of crêpe fabrics.

between the yarns of the crêpe fabrics, as shown in Figure 2. The average air resistance values of S1-2, S1-3, and S1-4 were 0.083, 0.063, and $0.066 \mathrm{kPa} . \mathrm{s} / \mathrm{m}$, respectively. Air resistance increased as the piqué became finer. 


\section{Effect of relative humidity on fabric tensile properties}

As shown in Figure 4, among all the mechanical properties, tensile properties of the samples showed the largest differences. Therefore, the effect of relative humidity on tensile properties was investigated further. The tensile extensibility (EM) in the weft direction of the crêpe fabrics was larger than that in the warp direction. The effect of humidity on EM was measured in both the warp and the weft directions under $10 \% \mathrm{RH}$ and $90 \% \mathrm{RH}$. The difference between the EM values under $10 \% \mathrm{RH}$ and $90 \% \mathrm{RH}$ in the warp direction was in the range of $0.2-0.8 \%$; thus, the effect of humidity was small. The subsequent discussion focuses on the fabric tensile properties in the weft direction.

Figure 5 shows the force-extension curves in the weft direction of S1-5 under 90\% RH. The total energy loss in the first cycle curve is comparatively larger than that in the other curves. The difference between the second and third curves is small. This tendency was observed for all the samples under all the humidity conditions. After the first tensile curve, the residual strain was defined as $\Delta \varepsilon$ in order to evaluate the irreversible strain after the extension, because once the crêpe fabrics were extended, the subsequent deformation would be small. This tendency was observed for all the samples.

In this study, all the samples were made from the same yarns of the same cotton fibers. Thus, the main source of the differences in tensile properties was the surface geometry of the fabrics.

Figure 6 shows the average EM-1 values of three specimens of each sample fabric plotted against relative humidity $(10-90 \% \mathrm{RH})$. The extensibility of the samples increased with relative humidity because of the nature of cotton fiber [11]. The EM-1 values of S1-2 (10 piqués per centimeter) and S1-3 (6 piqués per centimeter) were larger than those of S1-4 and S1-5 (without piqué) under all the RH conditions, mainly because the piqué shape increased the extensibility. According to the surface trace in Figure 2, the piqué height of S1-2 was the same as that of S1-3, but the trace length of S1-2 was greater than that of S1-3. In Figure 6, the difference between these two samples (S1-2 and S1-3) is clearer over $60 \% \mathrm{RH}$. In our previous study, the EM values of the same yarn used for weft markedly increased over 70\% RH. A similar tendency was observed for sample S1-2.

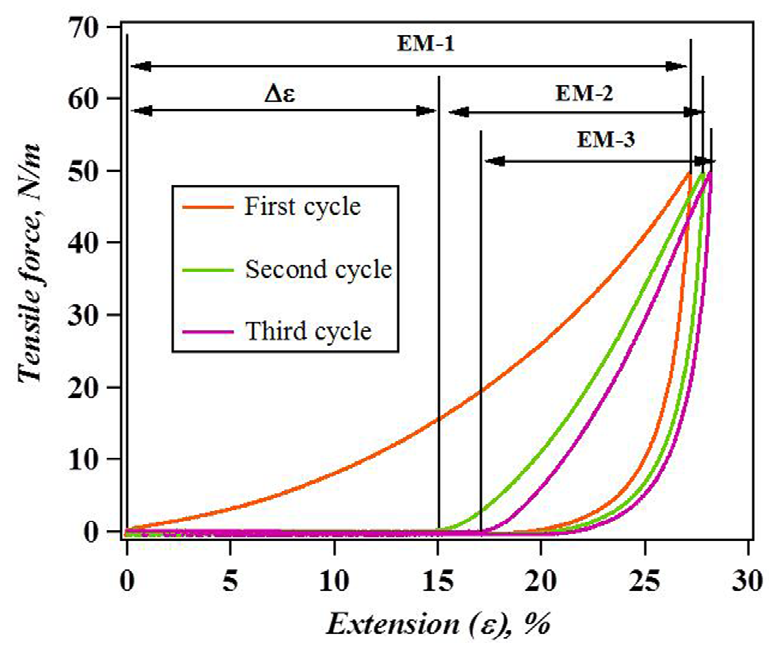

Figure 5: Tensile load vs. extension curves of $\mathrm{S} 1-5$ at $90 \% \mathrm{RH}, 25^{\circ} \mathrm{C}(\mathrm{EM}-1$ First-cycle extensibility; EM-2: Second-cycle extensibility; EM-3: Third-cycle extensibility; $\Delta \varepsilon$ : residual strain).

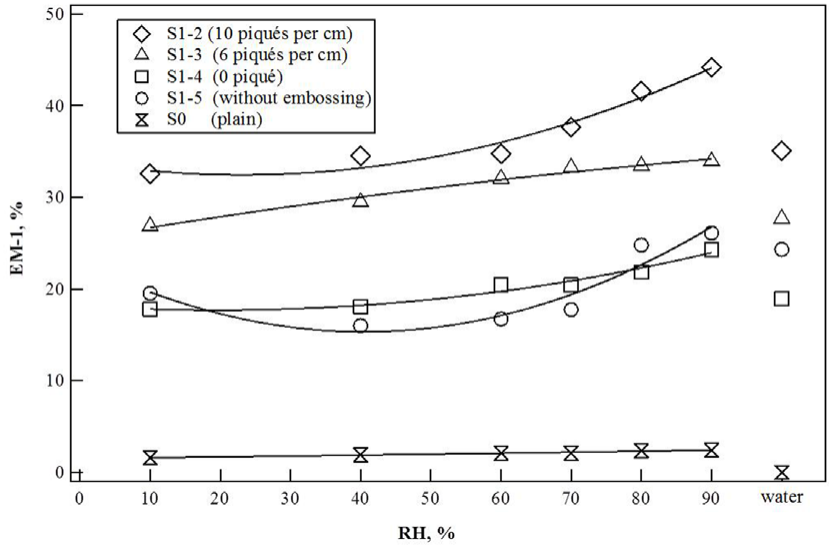

Figure 6: Effect of RH on first-cycle tensile extensibility (EM-1) of the fabric samples.

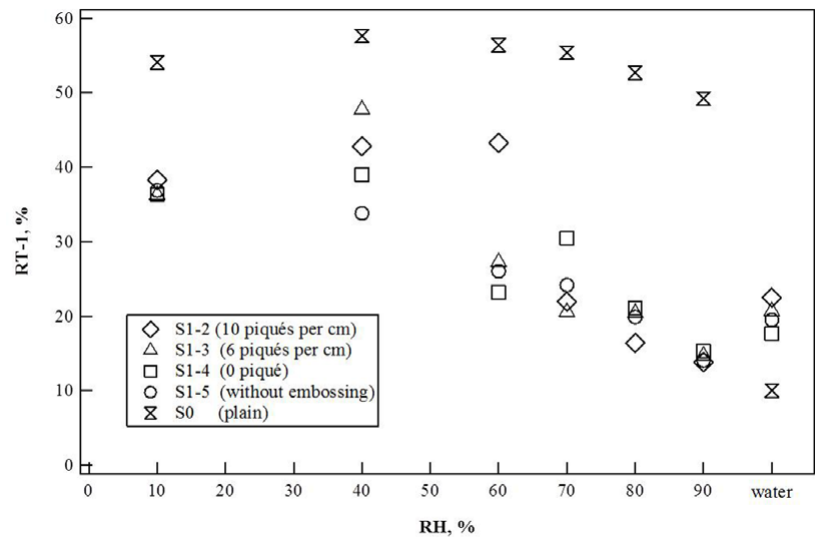

Figure 7: Effect of RH on first-cycle tensile resilience (RT-1) of the fabric samples.

In water, the EM-1 values of all the samples were smaller than those under $10 \% \mathrm{RH}$. Water penetrating into the fabric might increase the friction between the yarns and make the fabrics less extensible.

The relationship between RH and RT-1 is shown in Figure 7. The tensile recovery shows an inverse trend with relative humidity. Significant changes in RT- 1 were observed in the range of $40 \%-70 \% \mathrm{RH}$ at $25^{\circ} \mathrm{C}$. The differences among the crêpe samples were greater in this humidity range than outside it. In water, the RT- 1 values of S1-2 and S1-3 were the same as those of S1-4 and S1-5, whereas their EM values were larger. Although the large extensibility of piqué crêpe fabrics (S1-2 and S1-3) is beneficial, their poor recovery must be considered when using these fabrics for clothing. In light of the irreversible recovery, the residual strain was investigated.

Figure 8 shows that the $\Delta \varepsilon$ values of the pique fabrics (S1-2 and S13 ) were larger than those of the non-pique fabrics (S1-4 and S1-5). This difference became considerably larger when the $\mathrm{RH}$ was increased from $70 \%$ to $90 \%$. Additional piqué seemed to increase the extensibility and maintain the recovery below $70 \%$ RH. Table 3 lists the values of residual strain against tensile extension under different $\mathrm{RH}$ conditions for all the fabrics. The values of $\Delta \varepsilon /(\mathrm{EM}-1)$ for the crêpe fabrics at $90 \% \mathrm{RH}$ were in the range of $0.5-0.6$, indicating that the recovery of piqué decreases as humidity increases. From the viewpoint of clothing that allows free 


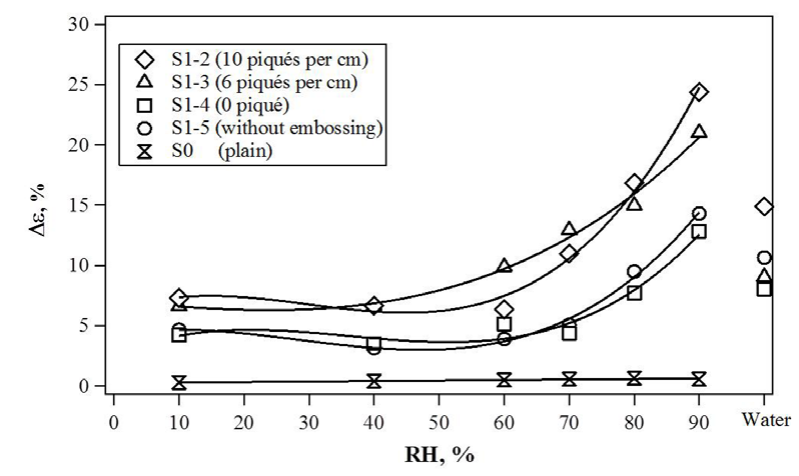

Figure 8: Effect of $\mathrm{RH}$ on residual strain $(\Delta \varepsilon)$ of fabric samples.

\begin{tabular}{|c|c|c|c|c|c|}
\hline $\begin{array}{c}\text { Humidity, } \\
\text { RH, \% }\end{array}$ & \multicolumn{5}{|c|}{$\Delta \varepsilon /(\mathrm{EM}-\mathbf{1})$} \\
\hline 10 & $\mathbf{S 0}$ & $\mathbf{S 1 - 2}$ & $\mathbf{S 1 - 3}$ & $\mathbf{S 1 - 4}$ & $\mathbf{S 1 - 5}$ \\
\hline 40 & 0.18 & 0.22 & 0.25 & 0.24 & 0.24 \\
\hline 60 & 0.24 & 0.19 & 0.23 & 0.19 & 0.20 \\
\hline 70 & 0.27 & 0.29 & 0.39 & 0.22 & 0.29 \\
\hline 80 & 0.27 & 0.41 & 0.45 & 0.35 & 0.38 \\
\hline 90 & 0.24 & 0.55 & 0.62 & 0.53 & 0.55 \\
\hline
\end{tabular}

Table 3: Residual strain $\Delta \varepsilon$ against maximum tensile extension EM-1.

body movement, high fabric extensibility is attractive. The extensibility of S1-2 was relatively stable in the humidity range below $70 \% \mathrm{RH}$. Thus, except under very high humidity, the extensibility of crêpe fabric with piqué can be used in designing new fabrics for women's clothing.

\section{Conclusion}

In this study, four crêpe fabrics (three embossed and one nonembossed) were used to investigate the effect of piqué and crinkle on tensile extensibility, resilience, and residual strain under varied relative humidity and in water at $25^{\circ} \mathrm{C}$.

The results of KES-FB measurements in a standard environment showed that the piqué appearance governs some physical properties, namely, EM2, WT2, B1, and 2HB1. The shear stiffness and hysteresis values of the crêpe fabrics were smaller than those of the plain fabric, but no difference was observed between the piqué and non-piqué fabrics. The most notable difference between the piqué crêpe and the non- piqué fabrics was their tensile extensibility. The effect of environmental humidity on the tensile properties of the fabrics was investigated, especially in the weft direction.

Piqué crêpe fabrics (S1-2:10 piqués per centimeter, S1-3: 6 piqués per centimeter) showed larger tensile extensibility (EM-1) and residual strain $(\Delta \varepsilon)$ than crinkled fabrics without piqué (S1-4) under all $\mathrm{RH}$ conditions. Even at $90 \% \mathrm{RH}$, the piqué structure was maintained, which indicates the high extensibility of piqué fabrics as compared to crinkled fabrics without piqué. However, the tensile resilience of the pique fabrics decreased and their residual strain increased over $80 \%$ RH. In conclusion, piqué crêpe is applicable to new fabrics for women's clothing, except under very high humidity.

\section{Acknowledgement}

We would like to express our gratitude to Mr. Shiro Takahashi, Takahashi Textile Co. Ltd., Shiga, Japan for providing the fabric samples used in this study. This work was supported by JSPS KAKENHI Grant Number 24220012 and $15 \mathrm{H} 01764$.

\section{References}

1. Celanese A (2001) Complete Textile Glossary. Celanese Acetate LLC, New York.

2. Yamashita S, Takatera M, Shinohara A (1997) Influence of fabric structure and twisted yarn on cotton crepe design part 2: Effect of weaving condition on shrinkage, rib shapes and number of ribs. Journal of the Textile Machinery Society of Japan 50: T155-163.

3. Ishikura H, Kase S, Nakajima M (1991) Study on crinkle design of crepe part 1 Crinkling mechanism of crepe. Textile Machinery Society of Japan Transactions 44: 62-69.

4. Ishikura H, Kase S, Nakajima M (1992) Study on crinkle design of crepe part 2: Analysis of the phase difference between contiguous hard twisted yarn in crepe. Journal of the Textile Machinery Society of Japan 45: T49-T58.

5. Ishikura H, Kase S, Nakajima M (1992) Study on Crinkle Design of Crepe Part 3: Experiment on the helix numbers in crepe fabrics. Journal of the Textile Machinery Society of Japan 45: T65-T70.

6. Ishikura H, Yang L, Kase S, Nakajima M (1992) Study on crinkle design of crepe part 4: Experiment on the helix numbers in crepe fabrics. Journal of the Textile Machinery Society of Japan 45: T154-T164.

7. Yang XH, Li DG (2007) Evaluation and control principle of the crepe effect on fabrics. Textile Research Journal 77: 779-784.

8. Ishikura H (1988) Study on Qualitative Improvement on Crepe summer Wear Journal of the Textile Machinery Society of Japan 41: T169-T176.

9. Yokura H, Endo S, Sukigara S (2013) Silhouette and handle design of silk chirimen fabrics for women's thin dress based on the mechanical properties. Journal of Textile Engineering 59: 133-139.

10. Raheel M (1995) Modern textile characterization methods: Objective Measurement of Fabric Hand. (1 ${ }^{\text {st }}$ edn), Marcel Dekker Inc.

11. Morton WE, Hearle JWS (2008) Physical properties of textile fibers ( $4^{\text {th }}$ edn) The Textile Institute, Wood head Publishing Limited, Cambridge, England. 